Kathleen R. Fellizar, MD'

Charlotte M. Chiong, MD ${ }^{1,2}$

'Department of Otorhinolaryngology

Philippine General Hospital

University of the Philippines Manila

${ }^{2}$ Philippine National Ear Institute National Institutes of Health University of the Philippines Manila
Correspondence: Kathleen R. Fellizar, MD Department of Otorhinolaryngology Ward 10, Philippine General Hospital Taft Avenue, Ermita, Manila 1000

Philippines

Phone: (632) 5264360

Fax: (632) 5255444

Email:orlpgh@yahoo.com

Reprints will not be available from the author

No funding support was received for this study. The authors signed a disclosure that they have no proprietary or financial interest with any organization that may have a direct interest in the subject matter of this manuscript, or in any product used or cited in this report

Presented at the Interesting Case Contest (1st Place) Philippine Society of Otolaryngology Head and Neck Surgery Midyear Convention, Legazpi City, Bicol, April 28, 2006

\title{
Langerhans Cell Histiocytosis: An Unusual Presentation
}

\begin{abstract}
Objective: To describe an unusual presentation of Langerhans cell histiocytosis in the craniofacial skeleton in a patient previously diagnosed with Pott's disease.
\end{abstract}

\section{Methods:}

\author{
Design: Case report. \\ Setting: Tertiary care center. \\ Patient: One (1)
}

Result: A 30-year-old male who previously underwent cervical spine surgery for Pott's disease, presenting with watery ear discharge and mandibular resorption was initially diagnosed with tuberculosis. On MRI, a mildly contrast-enhancing soft tissue mass involving the left infratemporal and middle cranial fossae consistent with residual or recurrent tumor as well as an inflammatory process was seen. He underwent transtemporal excision of the mass with external auditory canal blind sac closure and obliteration. Final histopathology revealed Langerhans cell histiocytosis. A review of slides of the specimen from the previous spine surgery was done and signed out as Langerhans cell histiocytosis.

Conclusion: Langerhans cell histiocytosis occurs rarely, but has frequent head and neck manifestations. It may also be confused with other diseases in the head and neck, such as tuberculosis, in this case. Otorhinolaryngologists and head and neck surgeons should be well aware that isolated lesions in the bony framework of the head and neck should include Langerhans cell histiocytosis in the differential diagnosis. Early detection is the key to preventing disease progression and instituting timely definitive management.

Key words: Langerhans cell histiocytosis, watery ear discharge, mandibular resorption 
Langerhans cell histiocytosis (LCH) comprise a group of idiopathic disorders characterized by the proliferation of specialized bone marrow-derived Langerhans cells as well as mature eosinophils. It is considered rare and the reported prevalence is higher among whites than other races and greater in males than females with a ratio of 2:1.

The head and neck are commonly involved especially the temporal bone. Previous reports noted that $25-30 \%$ of patients with various forms of this disease have temporal bone destruction. One case series has found nearly $50 \%$ involvement in the remainder of the head and neck. These consist mostly of isolated lesions of the mandible and skull. ${ }^{1}$

The frequency of head and neck manifestations, as well as possible confusion with other diseases in the head and neck make an understanding of the disease and its peculiarities important for the otolaryngologist. We report the rare case of a 30-yearold male presenting with watery otorrhea and mandibular resorption, the diagnostic examinations requested, the dilemma that arose with the case, and the surgical treatment done.

\section{CASE REPORT}

A 30-year-old male from Lucena City underwent cervical spine surgery in 2001 for Pott's disease. Histopathologic results were read as tuberculosis for which he took anti-tuberculosis medications for two months. The present consult involved a one- year history of recurrent, clear, watery nonfoul-smelling left ear discharge, which was resistant to medical management, associated with gradual decrease in the size of the mandible, clear discharge coming from the lower tooth sockets and loosening and eventual extrusion of the lower teeth. There was also gradual hearing loss in the left ear.

Three months prior to admission, the patient consulted an otolaryngologist who noted active milky-white discharge from the left ear with a positive fistula test, milky-white discharge from previous tooth extraction sites in the mandible and retrognathia. This led to a diagnosis of tuberculous otitis, left and tuberculous osteomyelitis of the mandible. A cranial CT scan was requested, but the patient was lost to follow-up.

Two months later, the patient returned with the CT scan, revealing a heterogenous soft tissue mass in the left masseter space with extension into the left middle cranial fossa. A bony defect involving the floor and lateral wall of the left middle cranial fossa was noted. The cochlea, jugular bulb and sigmoid sinus were absent in the left side (Figure 1). A soft tissue sarcoma was

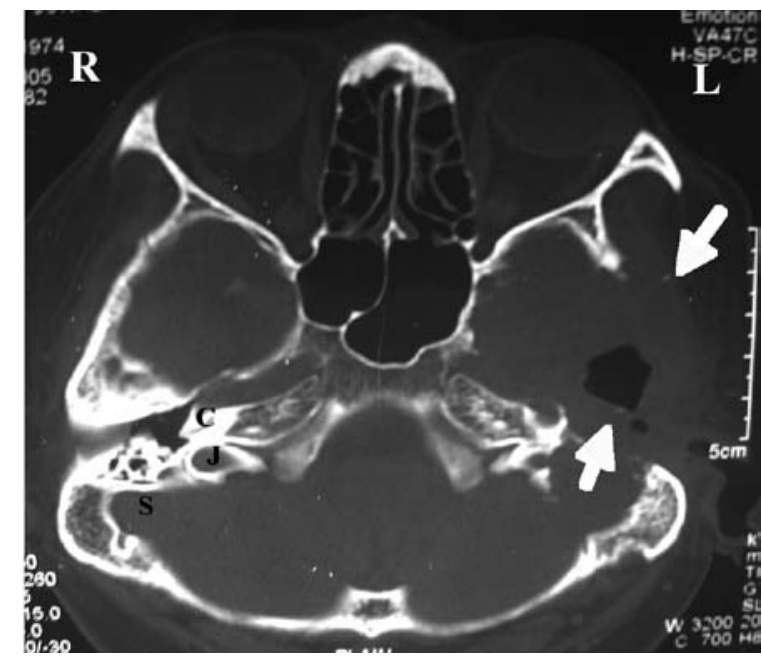

Figure 1. Cranial CT scan with bone window algorithm showing a large bony defect involving the floor and lateral wall of the left middle cranial fossa as well as destruction of the cochlea and the posterior fossa plate (white arrows). $\mathrm{C}=$ cochlea; $\mathrm{J}=$ jugular bulb; $\mathrm{S}=$ sigmoid sinus. Note the absence of the cochlea, jugular bulb and sigmoid sinus plate in the left side.

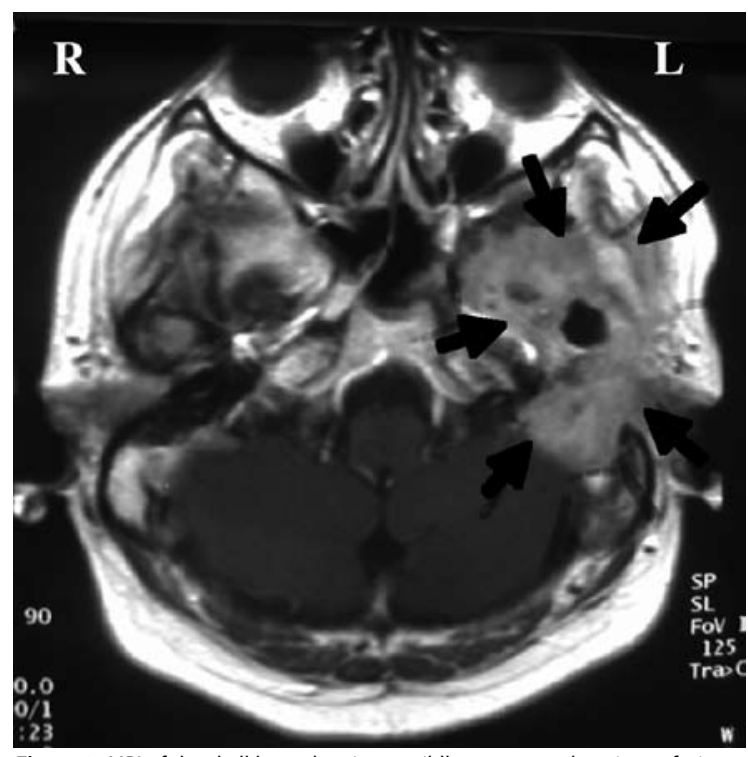

Figure 2. MRI of the skull base showing a mildly contrast-enhancing soft tissue mass involving the left middle cranial fossa (arrows).

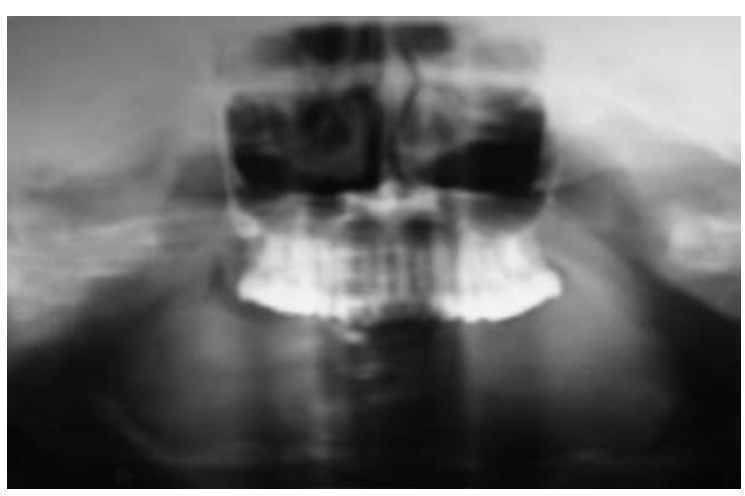

Figure 3. Panoramic radiograph of the patient, mandible absence is noted. 


\section{CASE REPORTS}

considered, for which cytologic correlation was recommended.

The patient was referred to a neurosurgeon who requested an MRI of the skull base. This showed a mildly contrast-enhancing soft tissue mass in the left infratemporal and middle cranial fossae (Figure 2). A biopsy was the next logical step but there was a dilemma on how to approach the mass.

Another otolaryngologist saw the patient and noted watery, clear, pulsatile non foul-smelling discharge from the left ear. Retrognathia was noted, for which a panoramic radiograph was done, showing total absence of the mandible (Figure 3). An assessment of CSF otorrhea secondary to TB lytic destruction with mandibular resorption was made.

In order to address both biopsy of the primary lesion and treatment of the CSF otorrhea, transtemporal excision of the mass with external auditory canal blind sac closure and obliteration under general anesthesia was done at the Philippine General Hospital. Intra-operative findings include the absence of the posterior bony external auditory canal wall, and an "eatenout" temporal bone. A fleshy mass was seen in the area of the mastoid cavity. Part of the mass was sent for frozen section which was read as chronic inflammation with gliosis. Near total gross excision of the mass was done. Blind sac closure of the external auditory canal was followed by temporalis muscle flap rotation and obliteration of the temporal bone defect to address the CSF leak.

Final histopathologic diagnosis was Langerhans cell histiocytosis. A review of slides of the specimen from the previous spine surgery was requested, which likewise revealed Langerhans cell histiocytosis. To strengthen the diagnosis, immunostaining with S-100 protein was done. Both specimens were positive.

The post-operative course was uneventful except for episodes of dizziness and vomiting. The patient was discharged after 12 days, but was again lost to follow-up. Despite repeated calls, the patient refused the recommendation to undergo chemotherapy.

\section{DISCUSSION}

Langerhans cell histiocytosis (LCH), formerly known as histiocytosis $\mathrm{X}$, denotes a group of diseases characterized by infiltration or proliferation of histiocytes in various body tissues. The clinical spectrum includes the acute fulminant, disseminated Letterer-Siwe disease, solitary or few, indolent and chronic, lesions of bone or other organs called eosinophilic granulomas, (under which the patient may fall) and the intermediate form called Hand-Schüller-Christian disease. ${ }^{2}$

$\mathrm{LCH}$ is seen in different ages, but a clear predominance exists for the pediatric age group. ${ }^{3} \quad$ It is a rare condition in adults. ${ }^{4}$ Thus, a 30-year-old male presenting with otorrhea, mandibular resorption and cervical spine erosion does not typify a patient with Langerhans cell histiocytosis.

Destruction of the temporal and mastoid bones manifest as mastoid swelling, middle ear polyps, and in this case, CSF otorrhea, and erosion of the posterior bony external auditory canal. Infiltration of the mandible will present with loose teeth and eventual resorption as seen in this patient. Vertebral collapse with spinal cord compression has occasionally been described, which may have happened in the patient when he was initially diagnosed with cervical Pott's disease four years prior to the onset of watery ear discharge.

There may be confusion with Langerhans cell histiocytosis and other diseases in the head and neck, particularly granulomatous inflammations, such as tuberculosis (TB). Many of the clinical features of Langerhans cell histiocytosis mimic this highly endemic disease in the Philippines. ${ }^{5}$ As seen in this case, radiographs were not able to differentiate between $\mathrm{TB}$ and $\mathrm{LCH}$. Even the final histopathology of the cervical lesion was initially read as tuberculosis.

Both Langerhans cell histiocytosis and tuberculosis may present with multisystem involvement. Symptoms in this patient presented in a sequential manner with cervical erosion, followed by mandibular resorption, and finally otorrhea, which is more in accordance with Langerhans cell histiocytosis. ${ }^{6}$ In the case of tuberculosis, symptoms usually appear simultaneously although progressive multi-organ involvement sequentially occurs in many cases.

Histologically, a typical tuberculous granuloma would normally be described as chronic granulomatous inflammation with caseation necrosis and Langhans' type giant cells mixed with chronic inflammatory infiltrates consisting of lymphocytes. (Figure 4a) In the patient's cervical spine specimen, cells were arranged in a granuloma-like pattern, and as such may have been mistaken for a tuberculous granuloma. (Figure 4b) Both diseases show aggregates of histiocytes. Histiocytes of tuberculosis are epithelioid and spindle-shaped. (Figure 5a) On the other hand, histiocytes seen in Langerhans cell histiocytosis are atypical, in that they are large, ovoid, mononuclear cells. (Figure 5b) Aside from this, LCH also presents with a large component of eosinophils in contrast to lymphocytes seen in TB.? 
CASE REPORTS

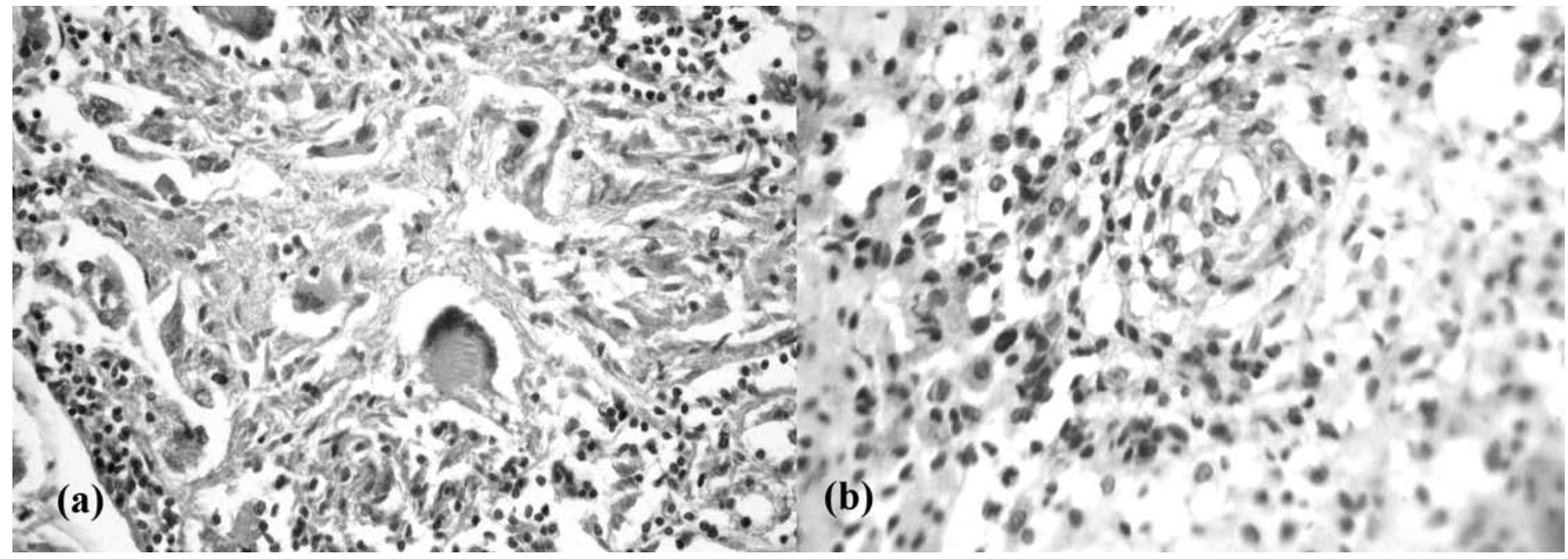

Figure 4. H\&E photomicrographs. (a) Typical tuberculous granuloma versus (b) granuloma seen in the cervical spine specimen of the patient.

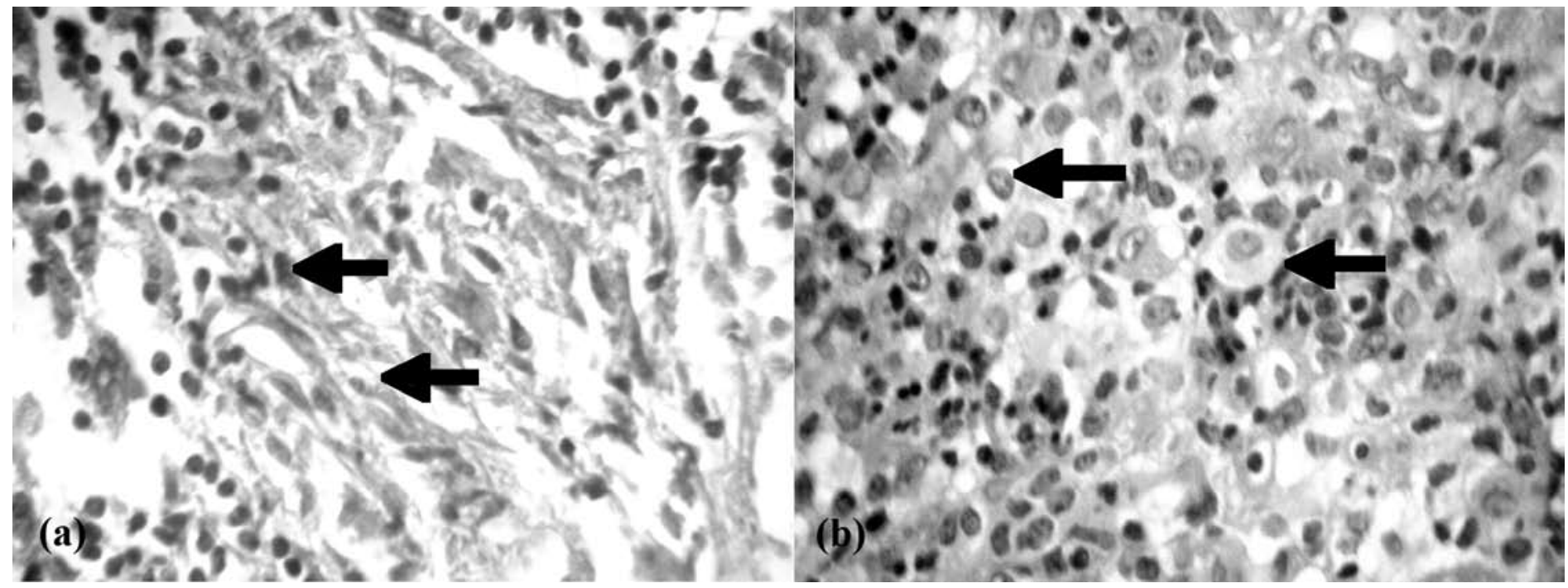

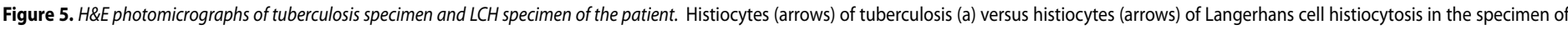
the patient (b).

S-100 staining strengthened the diagnosis of $\mathrm{LCH}$ in this case. Both normal and diseased Langerhans cells will stain positive for S-100. Tuberculosis cells do not.

The similarities and differences between Langerhans cell histiocytosis and tuberculosis noted in this case are summarized in Table 1.

The initial misleading histopathologic diagnosis of tuberculosis of the cervical spine specimen allowed progression of the disease to involve the mandible and then the temporal bone. The patient's poor follow-up record compounded this progression, adding to delays in diagnosis and treatment.

Transtemporal excision of the mass with blind sac closure of the external auditory canal was considered for the definitive
Table 1. Similarities and differences between Langerhans cell histiocytosis and tuberculosis noted in the case

\begin{tabular}{|l|l|l|}
\hline Multisystem involvement & $\begin{array}{l}\text { Langerhans cell histiocytosis } \\
\text { Present }\end{array}$ & $\begin{array}{l}\text { Tuberculosis } \\
\text { Present }\end{array}$ \\
\hline Appearance of symptoms & Sequential & $\begin{array}{l}\text { Often simultaneous, may } \\
\text { be sequential over time }\end{array}$ \\
\hline $\begin{array}{l}\text { Histologic arrangement } \\
\text { of cells }\end{array}$ & Granuloma-like pattern & $\begin{array}{l}\text { Chronic granulomatous } \\
\text { inflammation with casea- } \\
\text { tion necrosis and Langhans' } \\
\text { type giant cells }\end{array}$ \\
\hline Appearance of histiocytes & $\begin{array}{l}\text { Atypical; large, ovoid } \\
\text { mononuclear cells }\end{array}$ & Epitheliod, spindle-shaped \\
\hline Inflammatory infiltrates & Eosinophils & Lymphocytes \\
\hline S-100 reactivity & Positive & Negative \\
\hline
\end{tabular}


management of CSF otorrhea in this case while, at the same time, obtaining a good specimen for biopsy.

In retrospect, had a correct diagnosis been made at the time of cervical spine surgery, the resultant CSF otorrhea could have been prevented. Though initially managed by topical drops, the diagnosis of CSF otorrhea and definite management with external ear canal blind sac closure was very important. The latter is most relevant in preventing the possible lifethreatening condition of meningitis. However, the contralateral temporal bone is likewise at risk. Definitive treatment, in the form of chemotherapy consisting of low to moderate doses of methotrexate, prednisone, and vinblastine hopefully can save this patient from further lytic destruction of other bony sites. ${ }^{8}$ This option has been presented to the patient, as well as the possible side effects of chemotherapy, including hair loss and vomiting. The patient was not open to these particular side effects, thus refusing this therapeutic option.

Otorhinolaryngologists and head and neck surgeons should be well aware that isolated lesions in the bony framework of the head and neck should include Langerhans cell histiocytosis in the differential diagnosis because, as in the case of the different diseases that have plagued mankind throughout the centuries, early detection is still the key to preventing disease progression with timely definitive management.

\section{ACKNOWLEDGEMENT}

The authors wish to thank the following individuals from the University of the Philippines College of Medicine - Philippine General Hospital without whose help this paper would not have been possible: Dr. Jose Maria Avila, Chairman, Department of Pathology who was our resource person for pathology; Drs. Joselito Jamir and Romeo Villarta Jr. former chairman and consultant, respectively of the Department of Otorhinolaryngology, who were our scientific advisors; Dr. Gerardo Legaspi, consultant, Department of Neurosciences Section of Neurosurgery who was the co-managing neurosurgeon; and Dr. Sherjan Kalim, resident of the Department of Pathology for assisting with the photomicrographs.

\section{REFERENCES}

1. Jones RO, Pillsburry HC. Histiocytosis X of the head and neck. Laryngoscope. 1984;94:10311035.

2. Smith RJ, Evans JN. Head and neck manifestations of histiocytosis X. Laryngoscope, 1984;94:395399.

3. Kilpatrick SE, Wenger DE, Gilchrist GS, Shives TC, Wollan PC, Unni KK. Langerhans' cell histiocytosis (histiocytosis $\mathrm{X}$ ) of bone: A clinicopathologic analysis of 263 pediatric and adult cases. Cancer. 1995;76(12):2471-2484.

4. Malpas JS. Langerhans cell histiocytosis in adults. Hematol Oncol Clin North Am. 1998;12(2): 159-165.

5. Lorenzo PR, Martinez NV. Histiocytosis X: A pathologist's challenge. Philipp J Otolaryngol Head Neck Surg. 1992:140-145.

6. Bertram C, Madert J, Eggers C. Eosinophilic granuloma of the cervical spine. Spine. 2002;1:27(13):1408-13

7. Avila JM. Professor of Pathology, University of the Philippines College of Medicine. (personal communication, March 2006).

8. Davis SE, Rice DH. Langerhans cell histiocytosis: current trends and the role of the head and neck surgeon. Ear Nose Throat J. 2004 May:83(5):340-350. 